\title{
Visibility and hotspots of outdoor tobacco advertisement around educational facilities without an advertising ban: Geospatial analysis in Surabaya City, Indonesia
}

\author{
Hario Megatsari', Ilham A. Ridlo², Vilda Amir ${ }^{3}$ Dian Kusuma ${ }^{4}$
}

\begin{abstract}
INTRODUCTION Despite having over 60 million smokers in 2018, Indonesia still lacks tobacco control measures, including an outdoor tobacco advertising ban. This study aimed to provide evidence on the visibility and hotspots of advertisements around educational facilities in a city without a ban.

METHODS We collected data on the locations of outdoor tobacco advertisements and schools and universities in Surabaya city. We conducted buffer and hotspots analyses using ArcMap. Using Getis-Ord Gi* statistics, hotspot analysis identifies significant clusters with a high number of advertisements.

RESULTS We found 307 large and medium-sized outdoor tobacco advertisements and 1287 educational facilities (1199 schools, 88 universities). Almost $80 \%$ of those advertisements (237 units) were just $300 \mathrm{~m}$ away (10-minute walk) from primary schools and high schools in the city. More than half of all schools (652) and two-thirds of all universities (59) were inside hotspots where there were statistically significant clusters with a high number of advertisements. These hotspots were more densely populated and more-deprived areas.

CONCLUSIONS There was high visibility of large and medium-sized outdoor tobacco advertisements around educational facilities in the city without the ban.
\end{abstract}

\section{AFFILIATION \\ 1 Department of Health Promotion and Behavior Sciences, Faculty of Public Health, Universitas Airlangga, Surabaya, Indonesia 2 Department of Health Policy and Administration, Faculty of Public Health, Universitas Airlangga, \\ Surabaya, Indonesia \\ 3 Faculty of Public Health, Universitas Indonesia, Depok, Indonesia \\ 4 Centre for Health Economics and Policy Innovations, Imperial College Business School, London, United Kingdom \\ CORRESPONDENCE TO Dian Kusuma. Centre for Health Economics and Policy Innovations, Imperial College Business School, London, United Kingdom. E-mail: d.kusuma@imperial.ac.uk \\ KEYWORDS \\ visibility, hotspots, outdoor tobacco advertisements, educational facility, Indonesia}

Received: 15 July 2019

Revised: 12 September 2019

Accepted: 19 September 2019

\section{INTRODUCTION}

Indonesia is among the main contributors to global smokers, with 61.4 million current smokers in $2018^{1}$. The latest national health survey showed that the smoking prevalence among adults aged $\geq 15$ years remained high at $34 \%$ in 2018 and that among youth aged $10-18$ years it increased from $7.2 \%$ to $9.1 \%$ in the period 2013-2018 ${ }^{2}$. The proportion of adult smokers, who started very early at age 5-9 years, more than doubled from $0.6 \%$ to $1.5 \%$ in the period $1995-2013$, while those who began at age 10-14 years increased from $9 \%$ to $17.3 \%$ during the same period ${ }^{3}$.

One main factor is the lack of comprehensive national tobacco control. Indonesia is still not among the 181 countries that have signed and ratified the Framework Convention on Tobacco Control (FCTC), which provides legal support for comprehensive efforts ${ }^{4}$. At the national level, there are currently 
no bans on direct advertisements, point-of-sale advertisements, and product displays. The flagship national program has been the Presidential Decree $109 / 2012$, which encourages local governments to implement a smoke-free policy in selected facilities including those of health, education, and workplace. In these facilities, producing, selling, advertising, promotion and smoking of tobacco products are prohibited. Recent studies, however, showed only $67 \%$ of districts $(345 / 514)$ adopted the policy as of 2018 , with considerable variations in compliance rates from $17 \%$ in Jayapura to $78 \%$ in Bogor city ${ }^{5}$ (also Wahyuti W, et al, unpublished data, 2019).

Since cigarette advertising is causally linked to cigarette use among youth ${ }^{6,7}$, many countries have enforced the national ban on outdoor tobacco advertising including the United States (1998), United Kingdom (2003), and Sri Lanka (2006). While there is no such ban at the national level in Indonesia, few districts (15/514) have made the effort, but there are implementation issues such as enforcement and compliance. Banyuwangi district enacted the ban on main roads and sports arenas in 2016 , but a survey found high visibility of about 1300 advertisement materials a year later ${ }^{8}$. There is currently no such evidence in districts without the ban.

Literature is also limited in at least two ways. First, many studies are mainly older (1990s) and from high-income countries such as the United States $^{9-11}$. Second, since many nations have adopted a national ban on outdoor tobacco advertising since the FCTC in 2005, those studies have not employed the recently developed geospatial techniques. The hotspot analysis, for instance, that uses Getis-Ord $\mathrm{Gi}^{*}$ statistics to identify clusters ${ }^{12}$ has been increasingly used in infectious disease epidemiology research but not much in non-communicable disease, including tobacco control ${ }^{13,14}$.

This study aimed to provide evidence on the visibility and hotspots of outdoor tobacco advertisements around schools and universities in Surabaya city where there is no advertising ban. Surabaya is the capital city of East Java province and the second largest city of Indonesia, with over 3 million people in 2017. It was among the first district governments to implement smoke-free areas banning indoor smoking in selected facilities including schools since $2008^{15}$. However, it is currently lagging in more comprehensive tobacco control measures.

\section{METHODS}

We conducted a geospatial analysis of the visibility and hotspots of outdoor tobacco advertisements around schools and universities in Surabaya. There are two primary data: advertisement and educational facility data.

First, we collected data on large and mediumsized advertisements during October-November 2018 by surveying over 250 registered roads and streets (as per the mayor's regulation number 70 of $\left.2010^{16}\right)$ using motorcycles and cars. Variables included geocodes (latitude and longitude), types (videoboard, billboard, and banner), brand/product name, and picture. We used Google My Location App on smartphones to obtain the geocodes ${ }^{17,18}$.

Second, educational facility data include a comprehensive list of government and private schools and universities in Surabaya. We obtained the school data from the website of the city education office with variables: school name, level (primary, junior high, and senior high), ownership (government, private), and address. We obtained the university data from the website of the national higher education office with similar variables. Both school and university data were as of December 2018. We used Google Sheets and geocoding addons to convert the addresses into geocodes. Also, we collected published subdistrict demographic and socioeconomic data from the Statistics Bureau of the city.

The geographical analyses were conducted in ArcMap 10.6 using the World Topographic Map as a basemap. We used several geospatial tools: 1) geoprocessing/buffer tool to generate buffers of 100 $\mathrm{m}$ and $300 \mathrm{~m}$ around advertisements ${ }^{19-21} ; 2$ ) spatial join tool to calculate the number of advertisements that have at least one school within a buffer; 3 ) spatial join and dissolve tools to produce number of schools within an advertisement buffer; 4) kernel density tool to generate heatmap of advertisements and optimized hotspot analysis tool to produce the hot spots (defined as significant clusters with a high number of advertisements using 95\% significance levels); and 5) spatial join tool to produce number of schools/universities within hot spots. In the analyses, 
we represented each advertisement and facility as a point on the map while government universities as polygons because of typically larger areas.

\section{RESULTS}

Table 1 shows the descriptive statistics of outdoor tobacco advertisements and educational facilities of our analysis. There were 307 large and medium-sized advertisements, which included billboards (63\%), banners (31\%), and videoboards (7\%) (Appendix 1 shows sampled pictures). The three most prominent companies, including local companies such as PT. Djarum and PT. Gudang Garam and global companies such as PT. HM Sampoerna (Philips Morris International) owned most of the advertisements (90\%). There were 1287 educational facilities, including 1199 schools and 88 universities. Over

Table 1. Outdoor tobacco advertisements and educational facilities in Surabaya city, 2018

\begin{tabular}{|c|c|c|}
\hline Categories & n & $\%$ \\
\hline \multicolumn{3}{|l|}{ Advertisement by type } \\
\hline Billboard & 193 & 63 \\
\hline Banner & 94 & 31 \\
\hline Videoboard & 20 & 7 \\
\hline Total & 307 & \\
\hline \multicolumn{3}{|l|}{ Advertisement by company } \\
\hline PT. Djarum & 116 & 38 \\
\hline PT. HM Sampoerna & 83 & 27 \\
\hline PT. Gudang Garam & 73 & 24 \\
\hline Other companies & 35 & 11 \\
\hline Total & 307 & \\
\hline \multicolumn{3}{|l|}{ School by type (grades) } \\
\hline Primary school (6-12) & 684 & 57 \\
\hline Junior high school (13-15) & 346 & 29 \\
\hline Senior high school (16-18) & 169 & 14 \\
\hline Total & 1199 & \\
\hline \multicolumn{3}{|l|}{ School by ownership } \\
\hline Government & 397 & 33 \\
\hline Private & 802 & 67 \\
\hline Total & 1199 & \\
\hline \multicolumn{3}{|l|}{ University by ownership } \\
\hline Government & 7 & 8 \\
\hline Private & 81 & 92 \\
\hline Total & 88 & \\
\hline
\end{tabular}

One advert was excluded because it was outside of the city boundary used for spatial analysis. Other companies include PT. Bentoel International, PT. Wismilak, PT. Karyadibya Mahardika, PT. Kolang Citra Abadi, and PT. Nojorono Tobacco. The University of Airlangga has three separate campuses (counted as three facilities) but Sepuluh November Institute of Technology, the State Polytechnic in Electronics, and the State Polytechnic in Marine Engineering were within the same campus complex so were counted as one facility. half of the schools were at the primary school level, and two-thirds were private. Over $90 \%$ of universities were private.

Figure 1 (panel a) shows the visibility of outdoor tobacco advertisements using buffer analysis. The red dots show outdoor tobacco advertisements and grey lines show dissolved buffers of $100 \mathrm{~m}$ (about 5 -minute walk) and $300 \mathrm{~m}$ (about 10-minute walk) around schools. This result shows a high visibility of advertisements around school buffers. Table 2 shows the number of educational facilities with at least one advertisement inside school buffers and

\section{Figure 1. Visibility and hotspots of outdoor tobacco advert around educational facility in Surabava, 2018}
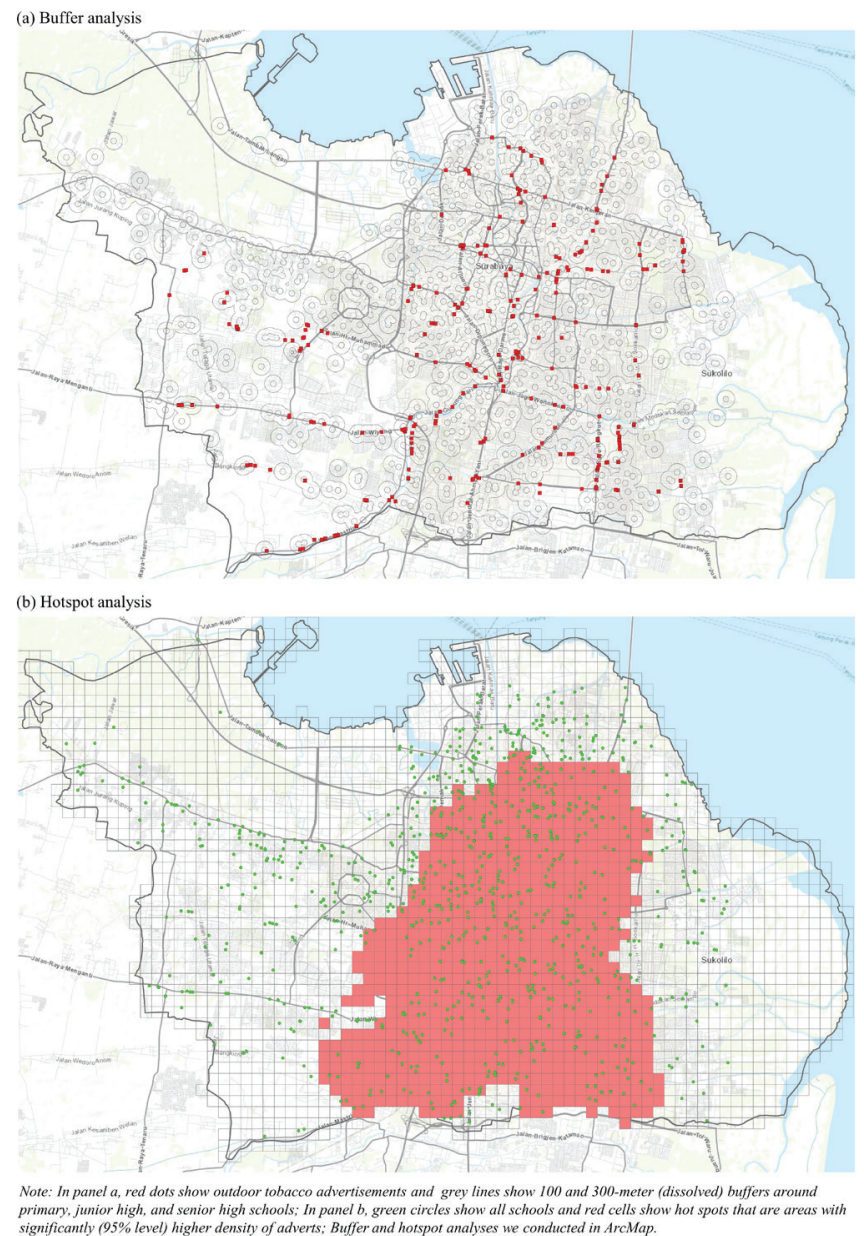
significantly (95\% level) higher density of adverts; Buffer and hotspot analyses we conducted in ArcMaj.

panels $a$ and $b$, subdistricts with hotspots are \#1-12 and \#1-18 in Appendix 5 respectively. This shows that by including those only partially within a hotspot gives the same results. Data were from published city and subdistrict reports by the Surabaya city Statistics Bureau. Not all subdistrict reports have data on poverty rates (proportion of poor households), when not available we summed the number of households or population in poorer categories (pra-sejahtera and sejahtera I) and divided by the number of households or population in each subdistrict. Hotspot status was based on the overlay of hotspots and subdistrict boundaries in Appendix 5. With hotspots = all or mostly within hotspot; No hotspots $=$ outside hotspots; $\mathrm{No}^{*}=$ some subdistrict area was within the hotspot. 
Table 2. Number and proportion of educational facilities and outdoor tobacco advertisements related to buffers and hotspots

\begin{tabular}{|c|c|c|c|c|c|c|c|c|}
\hline \multirow[t]{3}{*}{$\begin{array}{l}\text { Educational } \\
\text { facilitics }\end{array}$} & \multicolumn{3}{|c|}{$\begin{array}{l}\text { Number of facilities with at } \\
\text { least one advert within buffer }\end{array}$} & \multicolumn{3}{|c|}{$\begin{array}{l}\text { Number of adverts } \\
\text { within buffer (dissolved) }\end{array}$} & \multicolumn{2}{|c|}{$\begin{array}{l}\text { Number of facilities } \\
\text { within advert hotspot }\end{array}$} \\
\hline & & $100 \mathrm{~m}$ & $300 \mathrm{~m}$ & & $100 \mathrm{~m}$ & $300 \mathrm{~m}$ & & \\
\hline & Total & n $(\%)$ & n $(\%)$ & Total & n $(\%)$ & n $(\%)$ & Total & n $(\%)$ \\
\hline All schools & 1199 & $48(4)$ & 326 (27) & 307 & 54 (18) & 239 (78) & 1199 & 652 (54) \\
\hline Government & 397 & $20(5)$ & $113(28)$ & 307 & 27 (9) & $155(50)$ & 397 & 225 (57) \\
\hline Private & 802 & $28(3)$ & $213(27)$ & 307 & $34(11)$ & $188(61)$ & 802 & 427 (53) \\
\hline Primary & 684 & $29(4)$ & 185 (27) & 307 & $45(15)$ & 209 (68) & 684 & $378(55)$ \\
\hline Junior high & 346 & $13(4)$ & $92(27)$ & 307 & $22(7)$ & $152(50)$ & 346 & $183(53)$ \\
\hline Senior high & 169 & $6(4)$ & 49 (29) & 307 & $8(3)$ & 90 (29) & 169 & $91(54)$ \\
\hline All universities & 88 & $8(9)$ & $27(31)$ & 307 & $14(5)$ & $33(11)$ & 88 & $59(67)$ \\
\hline Government & 7 & $4(57)$ & $4(57)$ & 307 & $10(3)$ & $12(4)$ & 7 & $6(86)$ \\
\hline Private & 81 & $4(5)$ & $23(28)$ & 307 & $4(1)$ & $22(7)$ & 81 & $53(65)$ \\
\hline
\end{tabular}

Advert: advertisement. Buffer analysis, hotspot analysis and calculations were conducted in ArcMap. Hotspot analysis used Getis-Ord Gi* statistics. Hotspots show a significant cluster of a higher number of tobacco advertisements at a 95\% level.

the number of advertisements within dissolved school buffers. Results show that $27 \%$ of schools $(326 / 1199)$ and $31 \%$ of universities $(27 / 88)$ had at least one advertisement within $300 \mathrm{~m}$ from the facility. By ownership, visibility was similar between government and private schools, but it was higher around government universities $(57 \%$ vs $28 \%$, of government and private universities, respectively, had at least one advertisement within $300 \mathrm{~m}$ ). Moreover, results also show that $78 \%$ of advertisements $(239 / 307)$ and $11 \%$ of advertisements (11/307) were just $300 \mathrm{~m}$ from schools and universities, respectively. There were more advertisements around private schools (188 advertisements or $61 \%$ of total) and around primary

Table 3. Characteristics of subdistricts with and without advertisement hotspots

$\begin{array}{lcc} & \begin{array}{c}\text { Sulbdistricts } \\ \text { with hotspots }\end{array} & \begin{array}{c}\text { Sulbdistricts } \\ \text { with no } \\ \text { hotspots }\end{array} \\ \text { Subdistrict 12 } & 116258 & 82548 \\ \text { Population } & 6.1 & 13.6 \\ \text { Area size } \text { km }^{2} & 20333 & 7532 \\ \text { Population density per km² } & 21.6 & 16.9 \\ \text { Poverty rates } & & \\ \text { Subdistrict 18 } & 106559 & 80418 \\ \text { Population } & 9.1 & 13.0 \\ \text { Area size km } & & 8207 \\ \text { Population density per } \mathrm{km}^{2} & 15579 & 16.9 \\ \text { Poverty rates } & 21.6 & \end{array}$

schools (209 advertisements or $68 \%$ of total).

Figure 1 (panel b) shows the hotspots of outdoor tobacco advertisements using hotspot analysis. The green dots are schools, and the red-shaded areas are the hotspots (i.e. areas with significantly higher density of ads). Results show that the middle part of the city has a significant (95\% level) clustering of advertisements (the default ArcMap result is given in Appendix 2). This clustering is also shown in the kernel density map in Appendix 3. Table 2 shows the number and proportion of educational facilities within the hotspots. Results show high visibility around facilities, with $54 \%$ of schools (652/1199) and $67 \%$ of universities (59/88) inside the hotspot areas. Results also show that $57 \%$ and $53 \%$ of government and private schools were within hotspots, respectively, while the corresponding universities were $86 \%$ and $65 \%$, respectively. To better understand the hotspot areas, Table 3 shows the characteristics of subdistricts with and without advertisement hotspots. We overlaid the hotspots with the subdistrict boundary map and defined subdistricts with hotspots if all or most of a subdistrict area is within the hotspot. Twelve of 31 subdistricts in the city were defined as hotspots (Appendix 4). We then summarized the demographic and socioeconomic characteristics of areas with and without hotspots (Appendix 5). Results show that the subdistricts with hotspots are, on average, more densely populated (20333 vs 7532 people per $\mathrm{km}^{2}$ ) 
and have higher poverty rates $(21.6 \%$ vs $16.9 \%)$ compared to those without hotspots.

\section{DISCUSSION}

There was high visibility of large and medium-sized outdoor tobacco advertisements around educational facilities in a city without the ban. Many of those advertisements were large billboards and videoboards, from which young people were more likely to recall information, relative to smaller advertisements ${ }^{22}$. Almost $80 \%$ of those advertisements were about 10 minutes away from primary schools and high schools in the city, and more than half of schools and two-thirds of universities were inside the advertisement hotspots. Also, most of the advertisements were owned by the three biggest tobacco industries in the country, which have marketed cigarettes aggressively and attractively, especially to the youth ${ }^{23-25}$. All this encourages receptivity and favoritism to advertisements, which has shown to increase tobacco use among young people ${ }^{7,26}$. Results also show significant hotspots of ads, particularly in the middle areas of the city that are shown to be more densely populated and more impoverished. This could contribute to the increasing tobacco use among poorer populations, particularly youth ${ }^{27}$.

For global tobacco control, all this supports and justifies the crucial role of an effective ban on outdoor tobacco advertising in reducing exposure to tobacco marketing, particularly to young people. Even in settings that have had regulations to ban outdoor tobacco advertisements, implementation issues like low enforcement and compliance are likely to arise ${ }^{8}$. For Indonesia, this evidence should serve as a wakeup call for the government to ban outdoor tobacco advertisements, ideally a total ban but at least a near-school ban, in order to halt the increasing trend of smoking prevalence among youth $^{21,28}$. Currently, only $3 \%$ of districts have had some regulations to ban outdoor tobacco advertising. Concerted efforts should be made to extend the ban to the $97 \%$ (449) of the districts.

\section{Limitations}

Our study has at least two limitations. First, it has not included smaller sized advertisements. Further research should also assess the visibility of those advertisements. Second, this study only analyzed the visibility and hotspots around schools and universities.
Further studies should evaluate the visibility beyond schools, including health facilities, places of worship, and markets.

\section{CONCLUSIONS}

There was high visibility and hotspots of large and medium-sized outdoor tobacco advertisements around educational facilities in a city without the ban in Indonesia. This evidence supports the important role of an effective prohibition of outdoor tobacco advertisements in reducing the potential exposure to tobacco marketing to young people. This evidence should also serve as a wakeup call for the national and district governments in Indonesia to ban advertisements totally or at least near schools to halt the increasing trend of smoking prevalence among youth.

\section{REFERENCES}

1. World Health Organization. Factsheet 2018: Indonesia. Geneva, Switzerland: World Health Organization; 2018. https://apps.who.int/iris/bitstream/handle/ 10665/272673/wntd_2018_indonesia_fs.pdf;jsessionid= 7727 A 6 A E 2 E 3 ED 38 E 3044 D 6 F 235 F 607 DE? sequence $=1$. Accessed July 15, 2019.

2. National Institute of Health Research and Development, Indonesia Ministry of Health. Main results of Riskesdas (in Indonesian). Jakarta: NIHRD MOH; 2018.

3. Indonesia Public Health Association (IAKMI). Evidence of tobacco control in Indonesia (in Indonesian). Jakarta: Tobacco Control Support Center; 2014.

4. Kusuma D, Kusumawardani N, Ahsan A, Sebayang K, Amir $\mathrm{V}$, Nawi N. On the verge of a chronic disease epidemic: comprehensive policies and actions are needed in Indonesia. Int Health. 2019. doi:10.1093/inthealth/ihz025

5. Wahidin M, et al. Geographic, socioeconomic disparity and policy determinant of the adoption of smoke-free policy by districts in Indonesia 2004-2018. Int J Tuberc Lung. In Press.

6. National Center for Chronic Disease Prevention and Health Promotion (US) Office on Smoking and Health. Preventing Tobacco Use Among Youth and Young Adults. Atlanta (GA): Centers for Disease Control and Prevention (US); 2012. doi:10.1037/e603152012-001

7. Pierce JP, Sargent JD, Portnoy DB, et al. Association Between Receptivity to Tobacco Advertising and Progression to Tobacco Use in Youth and Young Adults in the PATH Study. JAMA Pediatr. 2018;172(5):444-451. doi:10.1001/jamapediatrics.2017.5756

8. Sebayang SK, Dewi DMSK, Lailiyah S, et al. Mixedmethods evaluation of a ban on tobacco advertising and promotion in Banyuwangi District, Indonesia. Tob 
Control. 2018. doi:10.1136/tobaccocontrol-2018-054443

9. Pucci LG, Joseph HM, Siegel M. Outdoor tobacco advertising in six Boston neighborhoods: Evaluating youth exposure. Am J Prev Med. 1998;15(2):155-159. doi:10.1016/S0749-3797(98)00034-8

10. Jacqueline L. Tailoring Outdoor Tobacco Advertising to Minorities in Los Angeles County. J Health Commun. 1998;3(2):137-146. doi:10.1080/108107398127427

11. Luke D, Esmundo E, Bloom Y. Smoke signs: patterns of tobacco billboard advertising in a metropolitan region. Tob Control. 2000;9(1):16-23. doi:10.1136/tc.9.1.16

12. Stopka TJ, Goulart MA, Meyers DJ, et al. Identifying and characterizing hepatitis $\mathrm{C}$ virus hotspots in Massachusetts: a spatial epidemiological approach. BMC Infect Dis. 2017;17(1):294. doi:10.1186/s12879-017-2400-2

13. McKay HS, Lessler J, Moore SM, Azman AS. What is a Hotspot Anyway? Am J Trop Med Hyg. 2017;96(6):12701273. doi:10.4269/ajtmh.16-0427

14. Chowell G, Rothenberg R. Spatial infectious disease epidemiology: on the cusp. BMC Med. 2018;16(1):192. doi:10.1186/s12916-018-1184-6

15. Surabaya City Government. Surabaya city regulation number 5/2008 on smoke free area. Surabaya. 2008. https://jdih.surabaya.go.id/pdfdoc/perda_99.pdf. Aaccessed September 3, 2019.

16. Mayor's regulation number $70 / 2010$ on calculation of advertisement rent. Surabaya. 2010. https://jdih. surabaya.go.id/pdfdoc/perwali_530.pdf. Accessed September 3, 2019.

17. Wohlgemut JM, Davies J, Aylwin C, et al. Functional inclusivity of trauma networks: a pilot study of the North West London Trauma Network. J Surg Res. 2018;231:201-209. doi:10.1016/j.jss.2018.05.045

18. Beldad A, Citra Kusumadewi M. Here's my location, for your information: The impact of trust, benefits, and social influence on location sharing application use among Indonesian university students. Comput Human Behav. 2015;49:102-110. doi:10.1016/j.chb.2015.02.047

19. Mistry R, Pednekar M, Pimple S, et al. Banning tobacco sales and advertisements near educational institutions may reduce students' tobacco use risk: evidence from Mumbai, India. Tob Control. 2015;24(e1):e100-107. doi:0.1136/tobaccocontrol-2012-050819

20. Ribisl KM, Luke DA, Bohannon DL, Sorg AA, MorelandRussell S. Reducing Disparities in Tobacco Retailer Density by Banning Tobacco Product Sales Near Schools. Nicotine Tob Res. 2017;19(2):239-244. doi:10.1093/ntr/ntw185

21. Luke DA, Ribisl KM, Smith C, Sorg AA. Family Smoking Prevention and Tobacco Control Act: Banning Outdoor Tobacco Advertising Near Schools and Playgrounds. Am J Prev Med. 2011;40(3):295-302. doi:10.1016/j.amepre.2010.11.018

22. Evans AT, Peters E, Keller-Hamilton B, et al. Warning Size Affects What Adolescents Recall From Tobacco Advertisements. Tob Regul Sci. 2018;4(3):79-87.
doi:10.18001/TRS.4.3.7

23. Nawi Ng, Weinehall L, Ohman A. 'If I don't smoke, I'm not a real man'- Indonesian teenage boys 'views about smoking. Health Educ Res. 2007;22(6):794-804. doi:10.1093/her/cyl104

24. Sebayang SK, Rosemary R, Widiatmoko D, Mohamad K, Trisnantoro L. Better to die than to leave a friend behind: industry strategy to reach the young. Tob Control. 2012;21(3):370-372. doi:10.1136/tobaccocontrol-2011-050223

25. Prabandari YS, Dewi A. How do Indonesian youth perceive cigarette advertising? A cross-sectional study among Indonesian high school students. Glob Health Action. 2016;9(1):30914. doi:10.3402/gha.v9.30914

26. Moran MB, Soneji S, Tan ASL, Choi K. Associations Between Exposure and Receptivity to Branded Cigarette Advertising and Subsequent Brand Preference Among US Young Adults. Nicotine Tob Res. 2019. doi:10.1093/ntr/ntz093

27. Henriksen L, Feighery E, Schleicher N, Cowling D, Kline R, Fortmann S. Is adolescent smoking related to the density and proximity of tobacco outlets and retail cigarette advertising near schools? Prev Med. 2008;47(2):210-214. doi:10.1016/j.ypmed.2008.04.008

28. Lopez ML, Herrero P, Comas A, et al. Impact of cigarette advertising on smoking behaviour in Spanish adolescents as measured using recognition of billboard advertising. Eur J Public Health. 2004;14(4):428-432. doi:10.1093/eurpub/14.4.428

CONFLICTS OF INTEREST

The authors have completed and submitted the ICMJE Form for Disclosure of Potential Conflicts of Interest and none was reported.

\section{FUNDING}

This research was funded by the Faculty of Public Health, Universitas Airlangga, Indonesia.

\section{AUTHORS' CONTRIBUTIONS}

HM and DK conceptualized the study. HM and IR conducted data collection. IR and DK analyzed the data. DK drafted and HM, IR, and VA provided inputs to the manuscript. All authors approved the final version of the manuscript.

\section{PROVENANCE AND PEER REVIEW}

Not commissioned; externally peer reviewed. 